\title{
Conditions in subjects with rheumatic diseases: pulmonary manifestations of vasculitides
}

Julia U Holle $e^{* 1}$, Frank Moosig', Klaus Dalhoff ${ }^{2}$ and Wolfgang $L$ Gross ${ }^{1}$

\begin{abstract}
Pulmonary involvement is a common complication of vasculitides, especially small vessel vasculitides.

This review provides an overview of vasculitic manifestations of the lung as well as of other organs involved in vasculitides. Furthermore, it provides the diagnostic procedures required to asses a patient with vasculitic lung involvement and gives an overview of current treatment strategies.
\end{abstract}

\section{Introduction}

The vasculitides comprise a heterogenous group of conditions that are currently classified according to the size of blood vessels predominantly involved [1,2]. Typically, vasculitides involving predominantly small- to medium-size vessels are associated with multiple organ involvement, including a predilection for the lung, whereas pulmonary involvement of large vessel vasculitides is rarer. This review therefore focuses on small vessel vasculitides and their pulmonary manifestations: pulmonary capillaritis leading to alveolar hemorrhage is the classic manifestation of small-vessel vasculitis and occurs most frequently in the context of the antineutrophil cytoplasmic antibody (ANCA)-associated vasculitides (AAVs). The AAVs represent the most frequent underlying condition of alveolar hemorrhage. Wegener's granulomatosis (WG), microscopic polyangiitis (MPA) and Churg-Strauss syndrome (CSS) share the features of small vessel vasculitis and a (variable) association with ANCAs and are therefore termed AAVs. Yet whereas MPA may be regarded as a 'pure' small- to medium-size vessel vasculitis, the other two AAVs (WG and CSS) feature more than just vasculitic manifestations. In WG the spectrum of organ manifestations encompasses

\footnotetext{
*Correspondence: j.holle@klinikumbb.de

'Vasculitis Center, University Hospital Schleswig-Holstein, Campus Lübeck and Klinikum Bad Bramstedt, Germany

Full list of author information is available at the end of the article
}

inflammatory mass formation ('granulomatous disease'), which is most prevalent in the upper and lower respiratory tracts and characterized by tumor-like infiltrative or destructive disease. In CSS, 'granuloma formation' may also be found, though less pronounced; furthermore, asthma, hypereosinophilia and eosinophilic organ infiltration are hallmarks of CSS.

\section{Wegener's granulomatosis}

Clinical features and histology

From the clinical point of view, WG is characterized by two features: mass formation and ANCA-associated small- to medium-size AAV. The former is usually restricted to the upper and lower respiratory tracts and its characteristic histology features constitute granulomatous and necrotizing inflammation, yet vasculitis may also be found within the granulomatous inflammation [2]. The latter may affect virtually any organ, with a predilection for lung and kidney involvement (necrotizing, predominantly small-vessel pauci-immune vasculitis, that is, manifesting as pulmonary capillaritis and crescentic glomerulonephritis) [3,4]. There is some evidence from in vitro and in vivo studies that ANCAs play a crucial role in the mediation of small-vessel vasculitis [5-7]. In WG, ANCAs are mainly directed against Proteinase 3 [4] and are implicated in the activation of polymorphonuclear neutrophils by interacting with Proteinase 3 expressed on the plasma membrane of these [5].

\section{Disease stages}

According to a concept by Fienberg [8], WG starts as 'granulomatous' disease of the upper and lower respiratory tracts and subsequently progresses to generalized ('systemic') disease characterized by clinical vasculitis manifestations, such as pulmonary capillaritis or necrotizing glomerulonephritis. This concept has been incorporated in the European definition of disease stages of AAV introduced in 1995 [9] and has been updated several times since then. In the current definitions [10], the localized disease stage, defined as manifestations restricted to the respiratory tract (that is, rhinitis, sinusitis, pulmonary masses) with no clinical signs of 
Table 1. Definition of disease stages in antineutrophil cytoplasmic antibody-associated vasculitis according to EULAR [8]

\begin{tabular}{lcclcl}
\hline $\begin{array}{l}\text { Clinical } \\
\text { subgroup }\end{array}$ & $\begin{array}{c}\text { Systemic } \\
\text { vasculitis outside } \\
\text { ENT and lung }\end{array}$ & $\begin{array}{c}\text { Threatened } \\
\text { vital organ } \\
\text { function }\end{array}$ & $\begin{array}{l}\text { Other } \\
\text { definitions }\end{array}$ & $\begin{array}{c}\text { Serum } \\
\text { creatinine } \\
(\boldsymbol{\mu m o l} / \mathbf{l})\end{array}$ & Pulmonary manifestations \\
\hline Localized & No & No & $\begin{array}{l}\text { No B-symptoms } \\
\text { ANCA typically negative }\end{array}$ & $<120$ & $\begin{array}{l}\text { Ulcerative bronchitis/bronchial stenosis in WG } \\
\text { Pulmonary masses'granuloma' in WG }\end{array}$ \\
Early systemic & Yes & No & $\begin{array}{l}\text { B-symptoms } \\
\text { ANCA negative or positive }\end{array}$ & $<120$ & As above \\
Generalized & Yes & Yes & ANCA positive & $<500$ & $\begin{array}{l}\text { As above } \\
\text { Sulmonary capillaritis, alveolitis }\end{array}$ \\
Severe & Yes & Organ failure & ANCA positive & $>500$ & As above with organ failure
\end{tabular}

ANCA, antineutrophil cytoplasmic antibody; ENT, ear-nose-throat; EULAR, European League Against Rheumatism; WG, Wegener's granulomatosis. Adapted from [11] with permission.

vasculitis (no pulmonary capillaritis), is differentiated from the systemic disease stages (early systemic, generalized and severe disease), all of which are associated with clinical signs of vasculitis. In the systemic disease stages, patients usually present with pronounced constitutional symptoms (weakness, fever, weight loss). Whereas early systemic disease is considered non-life-threatening (that is, occurring with arthritis, episcleritis or purpura), generalized disease is defined as organ- or lifethreatening (that is, due to glomerulonephritis or alveolar hemorrhage). In severe disease, organ failure has occurred due to systemic vasculitis manifestations (that is, renal failure; Table 1). The definition of these disease and activity stages [10] has facilitated the generation of evidence-based, stage-adapted treatment regimens. For most disease stages (except for localized disease), evidence from controlled trials is available to guide treatment decisions [11].

\section{Respiratory tract manifestations}

WG usually starts with symptoms due to upper respiratory tract involvement: manifestations affecting the nasal and oral cavity, the sinuses and the trachea are reported to occur in 75 to $93 \%$ of patients at diagnosis and in up to 99\% during the course of the disease $[3,4,12]$. Upper respiratory tract involvement not only occurs early in the disease course, but is the most frequent manifestation of WG [4], and for these two reasons is indicative of WG: patients typically present with rhinosinusitis with bloody discharge, crusting and epistaxis. Nasal crusting ('golden crusts') is a typical finding of endoscopic evaluation.

Granulomatous inflammation and/or mass formation may be found in the nasal cavity, sinuses and within the orbits but also frequently in the lower respiratory tract as pulmonary 'granuloma' [3,4] (Figure 1). Orbital masses, either perforating from the sinuses or developing within the orbit in isolation, are a serious complication of upper respiratory tract disease in 15 to $20 \%$ of patients [4]. The nature of granulomatous inflammation is destructive, as a significant proportion of patients develop signs of cartilage and bone erosion during the course of disease (that is, saddle nose deformity or orbital wall destruction), as has recently been shown in a study of localized WG patients [13]. Trachea and bronchi may also be affected by ulcerative or granulomatous inflammation, which may result in subglottic or bronchial stenosis.

The overall incidence of pulmonary involvement is frequent (between $60 \%$ and $85 \%$ ) and constitutes 'granulomatous' as well as 'vasculitic' manifestations $[3,4,12]$. Pulmonary nodules/masses ('granuloma') have been described on conventional radiography in around $60 \%$ of cases [3]. Diffuse alveolar hemorrhage due to vasculitis has been documented in 7 to $45 \%$ of patients $[3,4]$ (Figure 2).

\section{Respiratory tract manifestations of the localized disease stage}

The occurrence of 'granulomatous' manifestations of the upper and/or lower respiratory tract with no clinical signs of vasculitis has been defined as the localized stage (formerly the initial phase) [10], which is considered a transient stage before the patient develops systemic, clinical manifestations of vasculitis (which is present in all other disease stages). Yet, around 5 to $10 \%$ of patients remain in this disease stage and do not progress to systemic disease [13]. As outlined above, rhinitis, sinusitis, granulomatous mass formation (in sinuses, orbita and lung) as well as ulcerative or granulomatous and stenotic inflammation of trachea and bronchi (subglottic and bronchus stenosis) are manifestations of the localized stage. Cavitating nodules or masses with a diameter of greater than $3 \mathrm{~cm}$ on high-resolution computed tomography (HRCT) as well as parenchymal opacification are considered active lesions [14,15]. In contrast to generalized disease, the localized stage has been presumed mild and non-organ threatening, a finding that has recently been refuted by a cohort study on localized WG [13]. In this study, all patients developed upper 


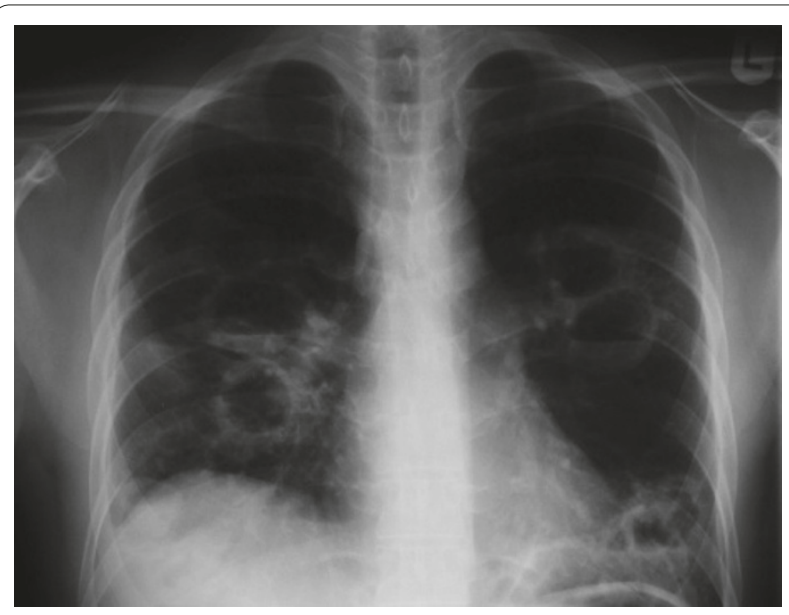

Figure 1. X-ray showing bilateral pulmonary granuloma in a Wegener's granulomatosis patient.

respiratory tract involvement. Furthermore, a significant proportion of patients developed destructive lesions within the upper respiratory tract: $30 \%$ saddle nose deformity; $28 \%$ nasal septal perforation; $18 \%$ suffered from space-consuming granulomatous masses leading to subglottic inflammation and stenosis; 20\% had pulmonary involvement with pulmonary mass formation. Due to resistant tumor-like mass formation and/or destructive, infiltrating inflammation, nearly $50 \%$ required highly potent immunosuppression (with cyclophosphamide) and $66 \%$ of patients acquired some kind of organ damage over the whole course of follow-up.

\section{Respiratory tract manifestations of the generalized disease stage}

'Granulomatous' manifestations may persist or even develop throughout the generalized disease stage, yet this stage is, per definitionem, associated with organ- and or life-threatening vasculitis manifestations. In the lung, diffuse alveolar hemorrhage (DAH) due to alveolar capillaritis is the classic manifestation of this disease stage. DAH has been reported to occur in 7 to $45 \%$ of patients and may develop in conjunction with glomerulonephritis, which is summarized under the term pulmonaryrenal syndrome. Hemoptysis and dyspnea are characteristic clinical signs of DAH, although a significant proportion of patients with DAH presents without hemoptysis. An increase in diffusing capacity of $>30 \%$ is suggestive of DAH in patients at risk. Diffuse uni- or bilateral alveolar shadowing on X-ray should raise the suspicion of DAH. HRCT scans typically show diffuse ground glass opacities. DAH can be confirmed by fiberoptic bronchoscopy, which may show diffuse bleeding arising from the pulmonary parenchyma and/or increasingly bloody lavage fluid in consecutive portions during

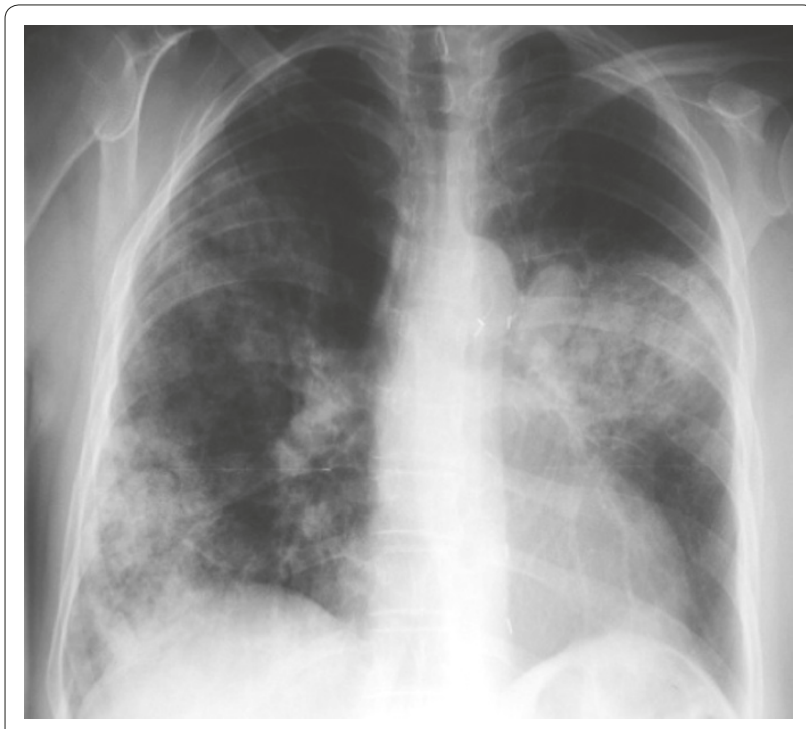

Figure 2. Diffuse bilateral infiltrations on plain X-ray due to alveolar hemorrhage as occurring in Wegener's granulomatosis, micorscopic polyangiitis and Churg-Strauss-syndrome. In order to verify that infiltrations are due to alveolar hemorrhage, bronchoalveolar lavage is required.

bronchoalveolar lavage. The amount of alveolar hemorrhage may be semiquantitatively assessed by the number and the intensity of staining of hemosiderinladen alveolar macrophages ('Golden score'). DAH may manifest as subclinical disease, but bleeding can also be severe and lead to a significant fall in hematocrit, hypovolemic shock and respiratory insufficiency. Mortality of DAH in AAV depends on severity and is estimated at 50 to $60 \%$ when mechanical ventilation is required $[16,17]$.

Apart from DAH, pulmonary involvement may also be present in the form of alveolitis that is not associated with capillaritis and DAH. Alveolitis is related to diffuse or interstitial pulmonary infiltrates on X-ray and a ground-glass pattern in CT. Active disease is associated with an increased neutrophil count in the bronchoalveolar lavage fluid [18]. An elevation of CD4+ T lymphocytes may also be found, mainly in conjunction with an interstitial infiltrate [18].

\section{Microscopic polyangiitis}

\section{Clinical features, disease stages and histology}

MPA may be regarded as 'pure' small- to medium-size vessel vasculitis that is associated with a positive ANCA status in more than $90 \%$ of cases, usually with perinuclear ANCAs (P-ANCAs) or myeloperoxidase-specific ANCAs (MPO-ANCAs). MPA has an incidence of three people per million per year and shows a slight male predominance $[19,20]$ with an average onset between 50 and 60 years of age. In contrast to WG, patients with MPA do not present with a classic localized stage of the disease. 
Ear-nose-throat (ENT) symptoms have been described to occur $[20,21]$, but granulomatous tumor-like or destructive processes of the upper and lower respiratory tract are lacking. At disease onset, constitutional symptoms are common $[19,21]$. Patients may present initially with either a non-life-threatening course ('early systemic disease', that is, arthralgia, arthritis, episcleritis), which may progress to 'generalized' disease, or acute organ- or lifethreatening disease ('generalized' or 'severe' disease stage, that is, necrotizing glomerulonephritis or DAH) within days or weeks. Similar to WG, there is a predilection for vasculitic manifestations of kidney (glomerulonephritis) and lung (alveolar capillaritis): glomerulonephritis has been reported to occur in 80 to $100 \%$ of patients [19-22] and is even more frequent than in WG; and alveolar hemorrhage due to capillaritis has been reported in 12 to $55 \%$ of patients [19-22] (Figure 2). In biopsy specimens, small- to medium-size necrotizing pauci-immune vasculitis is to be found with no evidence of granuloma formation.

\section{Respiratory tract manifestations}

DAH is the classic pulmonary manifestation in MPA and has been described to occur in 12 to $55 \%$ of patients [19-22]. MPA shows the highest frequency of DAH and/ or glomerulonephritis among the AAVs, occurring either as isolated organ involvement or together as pulmo-renal syndrome. As in WG, it has a wide spectrum, ranging from asymptomatic disease to a severe life-threatening stage.

Pulmonary fibrosis has been recognized as a pulmonary manifestation of MPA (Figure 3). Only few cases and a larger retrospective case series have been reported in the literature, most of which demonstrated an association of pulmonary fibrosis with MPO-ANCA-positive AAV or MPA [23-25], suggesting a pathogenic role of MPO or MPO antibodies in MPA-associated pulmonary fibrosis. Pulmonary fibrosis may develop after other clinical manifestations of MPA, but has also been reported to occur before disease onset [24], and it may have a usual interstitial pneumonia (UIP) or noninterstitial pneumonia (NSIP) pattern on HRCT and is associated with lower total lung capacity and increased mortality [26].

\section{Churg-Strauss syndrome}

\section{Clinical features, disease stages and histology}

CSS is characterized by peripheral blood hypereosinophilia, tissue eosinophilia, asthma and vasculitis $[1,2]$. The association with ANCAs is less strong; ANCAs can be detected in around $40 \%$ of individuals with CSS, in most cases P-ANCAs or MPO-ANCAs [27]. There is a substantial clinical overlap with the hypereosinophilic syndrome (HES). In fact, in some cases it might be difficult to strictly differentiate between CSS and HES.

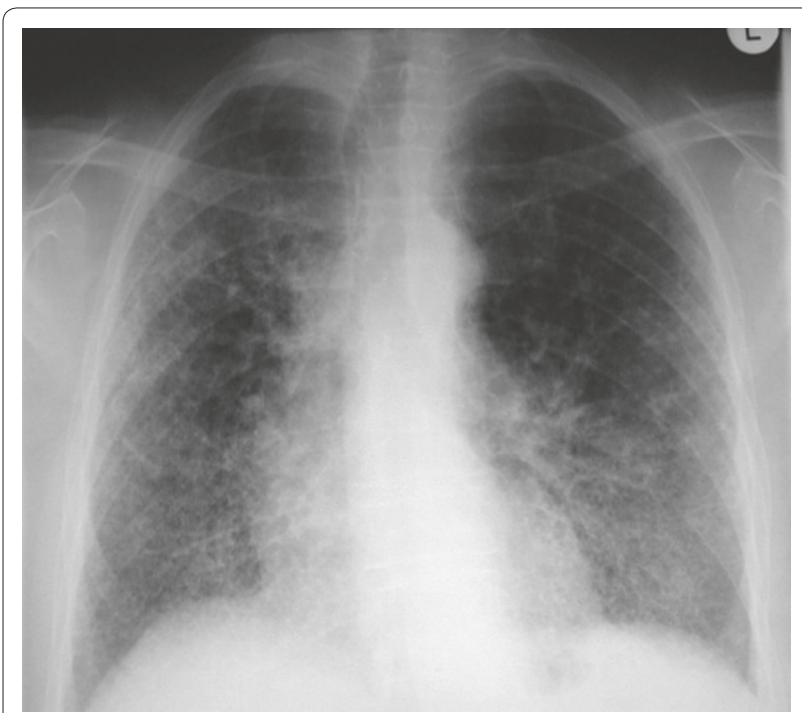

Figure 3. X-ray showing pulmonary fibrosis in microscopic polyangiitis.

According to recent classification proposals, CSS may be seen as a subtype of HES [28]. CSS usually develops in three distinct phases: the first phase is indistinguishable from poorly controlled asthma and may last for several years; the second phase is characterized by profound blood eosinophilia; and finally, with additional manifestations of small vessel vasculitis or histological evidence of vasculitis, the diagnosis of CSS can be established [29]. In general CSS may involve any organ system, although the lungs (90 to $100 \%$ ), the peripheral nervous system (approximately 70\%), the skin (50 to 70\%) and the heart (approximately 50\%) are predominantly affected [30,31]. According to the literature, ENT involvement is seen in about $50 \%$ of patients; in our own experience, sinusitis, polyposis or rhinitis are found in more than $90 \%$ if examination by an ENT specialist is part of the work-up (unpublished observation). Constitutional symptoms are common.

ANCAs are correlated with distinct clinical manifestations: in ANCA-positive CSS, classical vasculitis manifestations, such as glomerulonephritis, pulmonary vasculitis with DAH or peripheral neuropathy, are more frequent, whereas heart-involvement is seen more often in ANCAnegative CSS [29]. Evidence from genetic studies further supports the view of at least two distinct disease subtypes [32].

In the absence of surrogate parameters for vasculitis, the evaluation of biopsy specimens is crucial to differentiate between HES and CSS since the latter requires histological evidence of necrotizing vasculitis as long as no clinical surrogate such as glomerulonephritis is present. In the original publication by Churg and Strauss [33] three characteristic features were described: tissue 
eosinophilia, necrotizing vasculitis and granuloma formation. Tissue infiltration by eosinophils is very common and believed to represent a major pathogenic mechanism; however, it is not specific for CSS and cannot aid delimitation towards HES.

Definitions for disease stages and activity should be used as suggested for AAV (Table 1), although the evidence for those definitions was derived mainly from studies in WG and MPA. The Five Factor Score (FFS) for CSS was found to predict mortality and should be used as a prognostic tool $[34,35]$.

\section{Respiratory tract manifestations}

Respiratory tract involvement is very common in CSS. The vast majority of patients (>90\%) suffer from bronchial asthma. In spite of the high frequency of asthma in CSS patients, clinical features of asthmatic manifestations and subtypes of asthma have not yet been described in detail. There are no reliable markers to predict the development of CSS in asthmatics. In the majority of patients asthma is characterized by adult onset and a relatively low prevalence of inhalational allergies. Frequently, a tendency to more severe or 'difficult to treat' asthma is observed. In more than $80 \%$ of cases asthma precedes the onset of vasculitis by a median time of 4 years [36]. Lung function testing often shows persistent airflow obstruction in CSS patients with asthma [37]. Some reports link the use of a leukotriene receptor antagonist to CSS, although many experts believe that leukotriene receptor antagonists simply unmask CSS by allowing for reduction of systemic steroids. In a recent study, however, the association between leukotriene receptor antagonist and CSS could not be explained by steroid withdrawal in the majority of cases [38].

Reported frequencies of nasal polyposis, sinusitis and rhinitis vary and, according to our experience, are underestimated as long as no routine examination by an ENT specialist and/or cranial MRI is included in the work-up procedure. Upper respiratory tract manifestations in CSS can be distinguished from WG due to the lack of mass formation and destruction. Granulomatous lesions are a feature in biopsy specimens, yet the clinical or radiological appearance of granulomatous mass formation is usually not seen in CSS.

Pleural effusions can be seen in $10 \%$ of cases and might either be a sign of congestive heart failure due to heart involvement or a sequel of eosinophilic pleuritis.

Eosinophilic infiltration of the lung is common and may be detected as a patchy and migratory infiltrate on plain X-ray (Figure 4). Bronchoalveolar lavage is performed in order to prove eosinophilic alveolitis, and tissue infiltration may be seen in trans-bronchial lung biopsies. Other forms of alveolitis and mixed patterns (neutrophilic and lymphocytic alveolitis) also occur [39].
DAH as the clinical equivalent of lung capillaritis can occur but is less frequent than in WG and MPA [30] (Figure 2).

\section{Diagnostic procedure and therapy and outcome of AAV}

\section{Diagnostic work-up}

AAV patients should undergo a standardized multidisciplinary evaluation in order to determine disease stage and activity. It is recommended to treat AAV patients at or in cooperation with specialist centers [11]. All AAV patients require a work-up that includes examination of lung (X-ray, lung function testing and HRCT, and fiberoptic bronchoscopy with bronchoalveolar lavage if necessary) and kidneys (ultrasound, assessment of creatinine clearance and microscopic hematuria, red cell casts and proteinuria) and testing for ANCAs. In addition, WG patients should be seen by an otorhinolaryngologist and CSS patients require assessment of pulmonary function and allergy testing. At first presentation, confirmation of diagnosis should be sought by biopsy - for example, nasal mucosa and lung or kidney biopsy. Depending on disease symptoms and suspected organ manifestations, additional evaluations by a neurologist, ophthalmologist and dermatologist and/or additional technical examinations, such as MRI of sinuses and orbits, may be required.

Patients should be seen and evaluated in regular intervals (three- to six-monthly) to assess disease activity and adapt immunosuppressive therapy. Ideally, patients are evaluated by standardized and validated tools to assess disease activity and damage (such as the Birmingham Vasculitis Activity Score or the Vasculitis Damage Index) $[40,41]$.

\section{Treatment and outcome of Wegener's granulomatosis and microscopic polyangiitis}

Treatment follows a stage- and disease activity-adapted regimen due to evidence from controlled trials [11]. For remission induction in WG and MPA, methorexate (MTX) should be used in non-organ-threatening early systemic disease and cyclophosphamide in generalized disease in addition to glucocorticoids [42,43]. Rituximab may be an alternative for cyclophosphamide in the future $[44,45]$, even if not yet listed in the treatment recommendations as data have been published only very recently. For severe disease, namely acute renal failure, additional plasma exchange is recommended [46]. After successful remission induction (of 3 to 6 months), MPA and WG patients should be switched to maintenance therapy with medium-potent immunosuppression (azathioprin, MTX or leflunomide) [47-49]. It is recommended that the glucocorticoid dose should not exceed $10 \mathrm{mg}$ prednisone/day during maintenance. It is not yet 


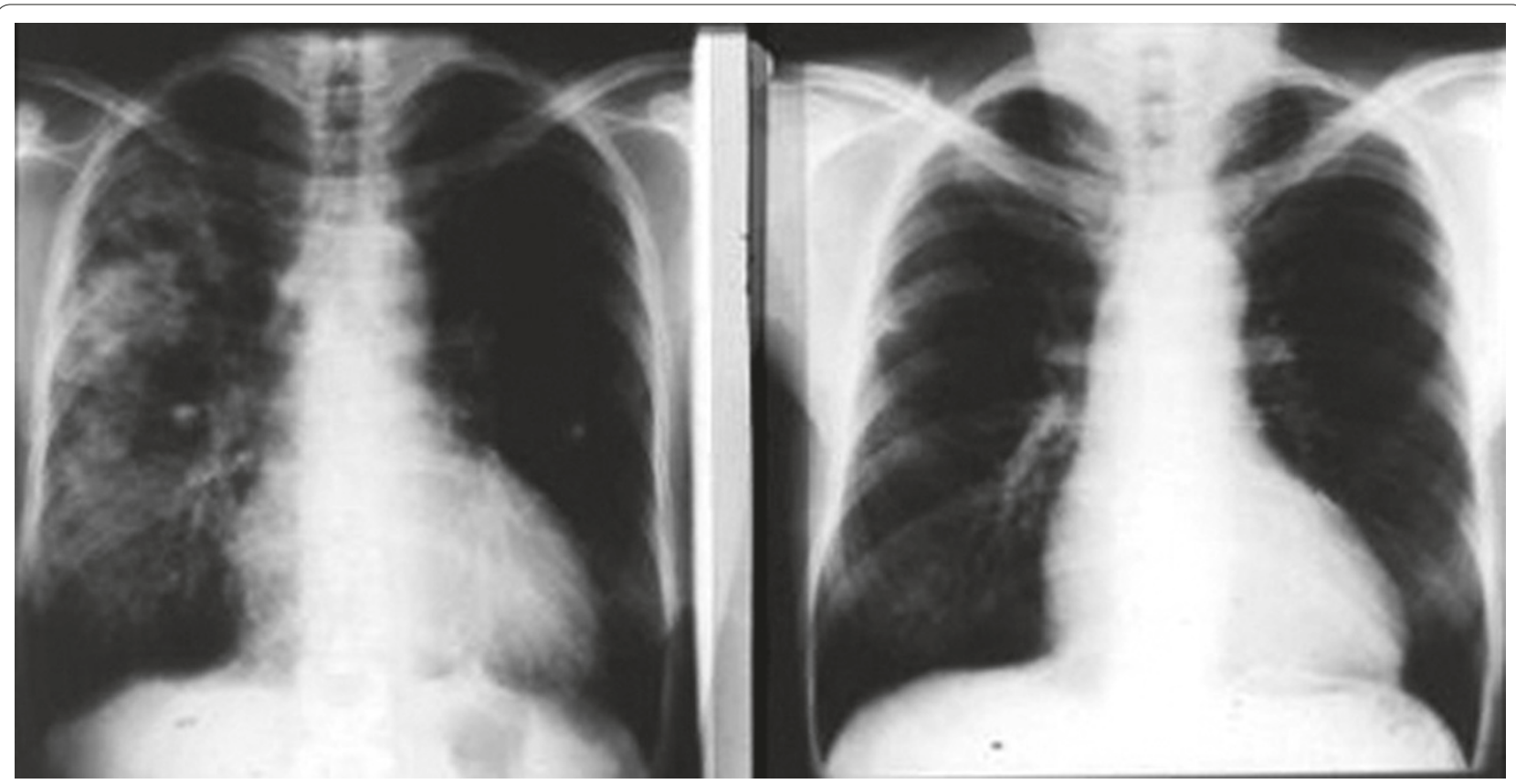

Figure 4. Diffuse, shadowy infiltrate in a patient with Churg-Strauss syndrome (on the left), promptly resolving under glucocortocoid therapy within 7 days (on the right).

known how long maintenance therapy is required but this is being investigated in current trials.

Treatment of localized WG and refractory disease represent the current challenges in the treatment of AAV. For localized disease, no controlled trials are available to support therapy decisions. Trimethoprim/sulfomethoxazole may be used for remission induction in upper airway disease in WG $[50,51]$ although it was not sufficient to control disease activity in a significant proportion of patients with persistent localized WG [13]. In clinical practice, patients in the localized disease stage are treated according to disease activity and severity: manifestations such as granulomatous sinusitis or subglottic stenosis may be treated with MTX. In the case of disease progression (that is, granulomatous sinusitis perforating the orbital wall and affecting the optic nerve) patients usually receive highly potent immunosuppression.

In spite of the use of highly potent and potentially toxic immunosuppression, such as cyclophosphamide, around 15 to $20 \%$ of patients (localized and generalized) do not respond to therapy ('refractory disease') $[4,13]$. In this situation, rituximab, infliximab, deoxyspergualin, antithymocyte globulin, mycophenolate mofetil or intravenous immunoglobulins are recommended [11], although controlled trials to support these recommendations are still lacking.

Older age, kidney involvement with impaired renal function, pulmonary manifestations at diagnosis and absence of ENT symptoms have been related to an adverse outcome and increased mortality $[4,52,53]$. Whereas several studies published in the 1990s showed an increased mortality of WG and MPA compared to the general population [54-57], a decrease in the standardized mortality ratios was reported in Swedish patients diagnosed before and after 1996 [58]; furthermore, a recent study reported no (more) increased mortality rates in WG patients diagnosed in the 1990s [59]. The evidence from controlled trials and the implementation of stageand disease activity-adapted regimens have particularly contributed to the improved outcome. Regardless, mortality rates during the first year after diagnoses remain excessively high (50\%), especially in those patients who are severely diseased (in the generalized or severe disease stage) and treated with highly potent immunosuppression [60]. Interestingly, patients died rather from infections than from acute vasculitis [60].

\section{Treatment and outcome of Churg-Strauss syndrome}

In general, principles of treatment for CSS are the same as for the other AAVs. A stage- and disease activityadapted approach is recommended. To guide therapy, the FFS as an additional instrument should be used [34]. Glucocorticoids (GCs) represent the mainstay of CSS treatment. In most cases relatively high doses have to be used for longer periods of time. As evidence accumulates that GCs are also the most significant risk factor for severe infections (see below) and long-term use is associated with a high burden of co-morbidity, therapy should 
aim to keep GC dose as low as possible. Concomitant treatment with high-dose inhaled corticosteroids may help to control asthma in CSS and lower systemic GC doses, although prospective data in this respect are not available. Medium-potent immunosuppressants, such as MTX or azathioprine, may be used for steroid sparing. In non-life- or organ-threatening CSS, for example, MTX might be used for induction of remission but subsequent relapse rates are high [61]. A FFS of $\geq 1$ usually triggers intense immunosuppression with cyclophosphamide [35]. Further indications for the use of cyclophosphamide are severe peripheral nerve involvement or failure of medium-potent drugs to control disease activity. Most experts recommend maintenance therapy after attaining remission for years, although proof of this concept is lacking in CSS.

Despite treatment with GCs and cyclophosphamide, about $10 \%$ of patients show refractory disease courses. The reported 5-year mortality rates in recent series are about $80 \%$ [62]. Several salvage therapies have been reported in case reports or small case series. Interferon- $\alpha$ is capable of inducing remission but long-term results are disappointing $[63,64]$. Rituximab, as in WG and MPA, may be a promising approach but data from larger series are still lacking [65]. Some efficiency was reported with tumor necrosis factor- $\alpha$ blocking agents [66].

A recently published case series reported the steroid sparing potential of mepolizumab, an IL-5 antibody, but failure to induce remission [67]. In another trial the steroid sparing potential was confirmed and the capability of mepolizumab to induce remission in refractory and relapsing CSS was shown [68]. Targeting IL-5 therefore represents the first targeted approach in CSS and warrants further investigations.

\section{Pulmonary manifestations of other vasculitides}

Among the small vessel vasculitides, Goodpasture's syndrome (GPS) is responsible for around $20 \%$ of alveolar hemorrhage due to pulmonary capillaritis. GPS is associated with antiglomerular basement membrane antibodies (ABMAs), and is rarely confined to the lungs but occurs usually in conjunction with glonerulonephritis (pulmonary-renal syndrome). ABMAs target type IV collagen in basement membranes of lungs and kidneys, which may become exposed and thereby accessible for ABMAs in the presence of inhalative noxae such as cigarette smoke or respiratory infections. GPS typically affects young adults (predominantly males) and older adults. In around $30 \%$ of patients, not only ABMAs but also P-ANCAs, usually directed against MPO, are present. The mainstay of therapy consists of GCs and cyclophosphamide. Furthermore, plasmapheresis should be performed in patients with pulmonary-renal syndrome and in patients with isolated glomerulonephritis when there is a chance for renal recovery (reviewed in [69]).

Rarely, DAH may occur as a manifestation of HenochSchönlein purpura (HSP) and cryoglubulinemic vasculitis $(\mathrm{CV})$, both of which are small vessel immune complex vasculitides. HSP (incidence 20 people per 100,000 per year) is characterized by immune deposits including IgA. It usually affects young children, with a male predominance. The classic triad of HSP is purpura (due to leucocytoclastic vasculitis of small skin vessels), arthritis and abdominal pain (due to gastrointenstinal vasculitis). Deposition of immune complexes to the alveolar basement membrane may lead to immune complex pneumonitis and leucocytoclastic capillaritis with subsequent DAH. Corticosteroids reduce duration and severity of joint and abdominal pain but do not prevent the development of nephritis. A wide range of immunosuppressants has been used to control disease activity, such as azathioprine, mycophenolate, cyclosporine and cyclophosphamide, yet there is currently not enough data available from controlled trials to indicate that any of these treatments are of definite benefit. Regarding cyclophosphamide, a recent study has shown that the combination of cyclophosphamide and GCs is not superior to GC treatment alone. Controlled trials are needed to guide treatment strategies in HSP (reviewed in [70]).

Around $2 \%$ of patients with CV present with DAH. CV may occur as primary 'essential' vasculitis or - and much more frequently - as secondary vasculitis, mostly due to infection with the hepatitis $\mathrm{C}$ virus. Typical CV manifestations are purpura, arthritis, polyneuropathy and glomerulonephritis (membranoproliferative glomerulonephritis type 1) [71]. In essential CV, GC treatment in conjunction with medium- to highly potent immunosuppression is recommended [11]. For hepatitis $C$ virusassociated $\mathrm{CV}$, anti-viral therapy is indicated. Rituximab may also be of benefit in the treatment of CV [11].

Small vessel vasculitis with lung involvement and consecutive alveolar hemorrhage may also develop rarely in collagen vascular diseases (such as systemic lupus erythematosus and systemic sclerosis).

Panrarteritis nodosa (PAN) is a systemic necrotizing vasculitis that predominantly affects medium-size arteries and may lead to stenosis or formation of microaneurysms, which can rupture and cause major bleeding. PAN is primary in the majority of patients but may also occur in association with viral infections, especially with hepatitis B virus. Apart from constitutional symptoms, peripheral neuropathy, skin involvement (livedo, purpura, digital ischemia), gastrointestinal involvement with bleeding and perforation, renal artery stenosis and hypertension are common [72]. Pulmonary involvement (lung infiltrates, pleural effusions) is rare (in around $4 \%$ of patients [72]). For hepatitis B-related PAN, the use of 
GCs and anti-viral agents is recommended. Plasmaexchange also seems successful in remission induction [73]. Non-infectious PAN is treated by GCs in conjunction with medium- to highly potent immunosuppressants.

Large vessel involvement of the lungs is found in two conditions, Takayasu arteritis and Behcet's disease (BD). Takayasu arteritis is a large vessel vasculitis mainly affecting young females in Japan and Southeast Asia. Most frequently, subclavian and carotid arteries are involved followed by adominal aorta and mesentery arteries. Brachiocephalic involvement may also occur, usually in conjunction with Takayasu arteritis inflammation at other sites. Isolated pulmonary artery involvement is rare [74]. Stenosis and occlusion is the typical complication, but dilatation and aneurysms may also be found. Patients should receive GCs and an adjunctive immunosuppressive agent, such as azathioprine, MTX or cyclophosphamide, for remission induction [73]. Reconstructive surgery should be performed when the patient is in remission if possible [73]. BD is a rare multisystemic and chronic inflammatory disorder that is associated with recurrent oral and genital ulcers, eye involvement (uveitis) and skin lesions (for example, erythema nodosum). It is most commonly found in young males and occurs most frequently in countries along the old silk route. There is a strong association with HLA-B51 in BD patients. The most common vascular involvement of BD is venous thrombophlebitis. Pulmonary artery vasculitis is present in $5 \%$ of cases and may lead to arterial and venous occlusion/thrombosis, aneurysms, infarction, hemorrhage and arteriovenous shunts. BD is the most common cause of pulmonary artery aneurysms (reviewed in [75]). If untreated, the mortality rate of $\mathrm{BD}$ patients with pulmonary artery aneurysms is $30 \%$ within 2 years. Treatment for BD consists of GCs plus adjunctive conventional immunosuppressants depending on disease manifestation and activity [76]. GCs plus cyclophosphamide may be effective in the treatment of aneurysmal dilatation.

Importantly, thromboembolisms may occur not only in BD but also in other vasculitides, especially in AAV [77]. A recent study showed that around $12 \%$ of AAV patients develop thromboembolism, usually during active disease [77].

Vasculitis related to drugs and occupational exposure Drugs such as propylthiouracil, gemcitabine, transretinoic acid and cocaine may also cause pulmonary capillaritis and DAH and are often associated with the presence of ANCAs [78]. Moreover, certain occupational exposures, such as to silica from specific farming tasks related to harvesting, have been suggested to be associated with AAV in case-control studies [79], but the data are controversial [80].

\section{Pulmonary infections as a comorbidity in vasculitides}

Risk of infection under immunosuppressive therapy

Infections in AAVs may be related to immunosuppressive therapy or the severity of the disease or both [81] and have been reported to occur in 6 to $55 \%$ of AAV patients $[82,83]$. In particular, high doses of GCs (often defined as $30 \mathrm{mg}$ prednisolone/day) and cyclophosphamide have been shown to be associated with infections in AAVs [84]. The dose of oral cyclophosphamide at the time point of infection as well as the cumulative oral cyclophosphamide dose were identified as risk factors [84]. Moreover, the rate of infections within the first 3 years of follow-up was related to the cumulative doses of cyclophosphamide and GCs [84]. Biologics are increasingly used for remission induction in AAV, with similar risk of infection compared to conventional therapy: in a randomized controlled trial of oral cyclophosphamide versus rituximab, the rates of infections in both arms were similar (around $7 \%$ of subjects had infections of grade 3 or higher) [44].

In refractory $\mathrm{AAV}$, even more intensive therapy may be administered, as biologics are often used in conjunction with medium- or highly potent immunosuppression. Serious infections were reported in $20 \%$ of refractory AAV patients treated with rituximab plus additional medium- or highly potent conventional immunosuppression, most of whom had pneumonias (14\%) [85]. Under anti-thymocyte globulin or deoxyspergualin in combination with GCs, even $40 \%$ and $78 \%$ of patients, respectively, suffered from infections $[86,87]$.

\section{Time point and kind of infection during the course of disease}

A study on risk factors for major infection in WG found that half of the major infections occurred within 3 years after WG diagnosis [84]. Furthermore, infections and not active vasculitis represent the main cause of 'early mortality' (mortality within the first year of diagnosis) in AAVs. 'Early mortality' was higher in study populations with more severe disease (in the generalized or severe stage of the disease) who received more intensive immunosuppression (cyclophosphamide or cyclophosphamide plus plasma exchange) [60]. In summary, patients seem to be most vulnerable to infections shortly after diagnosis. Whether this relates to the intensive immunosuppression required for remission induction or whether the disease and disease activity itself also accounts for a suppression of the immune system and an increased risk of death has not been determined.

Most of the controlled trials in AAV give the rate of infection, but do not specify the kind of infection $[42,43]$. Yet, a large retrospective study on WG patients and major risk factors for infections reported that pneumonia 
is one of the most frequent infectious complications under immunosuppression in AAVs [84]. Pneumonia accounted for $36 \%$ of all major infections, followed by viral infections (17\%). Likewise, lower respiratory tract infection has been reported as the most frequent infection in refractory AAV patients treated with rituximab and deoxyspergualin [86,87]. An intensified diagnostic approach including bronchoscopy with bronchoalveolar lavage is recommended in immunosuppressed patients with pneumonia because of the broad spectrum of pathogens and the uncertainties of empirical antimicrobial coverage in this population.

Pneumocystis jirovecii pneumonia (PJP) is a dreaded complication of immunosuppression and has been shown to occur most frequently in patients undergoing intense remission induction therapy [88]. Furthermore, among AAV patients, those with WG seem particularly at risk of developing PJP [81]. Without the use of PJP prophylaxis, the incidence of PJP was reported to be up to $20 \%$ [82]. Age, as well as a low lymphocyte count before and during therapy and prolonged GC doses of $>15$ to $20 \mathrm{mg} /$ day, are risk factors for PJP [88-91]. Although there are no controlled data on PJP prophylaxis in AAV, it is recommended as infection rates were much higher in trials not using prophylaxis compared to trials encouraging it $[82,92]$. Mahr and colleagues [93] reported no more occurrence of PJP since the introduction of PJP prophylaxis. PJP prophylaxis with trimethoprim/sulfomethoxazole is encouraged by European guidelines in all patients receiving cyclophosphamide [11].

\section{Conclusion}

The AAVs share the features of small vessel vasculitis and a (variable) association with ANCAs. Pulmonary capillaritis is the classic manifestation of small vessel vasculitis, occurring in all of the three AAVs. In WG the spectrum of the disease also encompasses mass formation ('granulomatous disease'), which is most prevalent in the upper and lower respiratory tracts (that is, pulmonary granuloma). In CSS, 'granuloma formation' may also be found, though less pronounced; furthermore, asthma and eosinophilic organ infiltration, such as eosinophilic alveolitis, are hallmarks of CSS. GCs and cyclophosphamide are the mainstay of remission induction in generalized disease (such as pulmonary capillaritis), and there is good evidence for the use of maintenance therapy (MTX, azathioprine or leflunomide) in conjunction with GCs in WG and MPA. Rarely, other vasculitides are associated with pulmonary manifestations: DAH may also occur in GPS, HSP, CV and collagen vascular diseases. Pulmonary artery occlusion due to thrombosis and pulmonary artery aneurysms are a feared complication in $\mathrm{BD}$. Infections, particularly those affecting the lower respiratory tract, remain a major problem under intense immunosuppression, including biologics. Yet, it is suggested that PJP prophylaxis is effective in patients receiving cyclophosphamide.

This article is part of the series Comorbid conditions in subjects with rheumatic diseases, edited by Daniel Aletaha and Thomas Dörner.

Other articles in this series can be found at

http://arthritis-research.com/series/comorbid

\section{Abbreviations}

$A A V$, antineutrophil cytoplasmic antibody-associated vasculitis; ABMA, antiglomerular basement membrane antibody; ANCA, antineutrophil cytoplasmic antibody; BD, Behcet's disease; CSS, Churg-Strauss syndrome; CT, computed tomography; $\mathrm{CV}$, cryoglubulinemic vasculitis; $\mathrm{DAH}$, diffuse alveolar hemorrhage; ENT, ear-nose-throat; FFS, Five Factor Score; GC, glucocorticoid; HES, hypereosinophilic syndrome; HRCT, high-resolution computed tomography; HSP, Henoch-Schönlein purpura; L, interleukin; MPA, microscopic polyangiitis; MPO-ANCA, myeloperoxidase-specific antineutrophil cytoplasmic antibody; MRI, magnetic resonance imaging; MTX, methorexate; PAN,

panarteritis nodosa; P-ANCA, perinuclear antineutrophil cytoplasmic antibody; PJP, Pneumocystis jirovecii pneumonia; WG, Wegener's granulomatosis.

\section{Competing interests}

The authors declare that they have no competing interests.

\section{Author details}

'Vasculitis Center, University Hospital Schleswig-Holstein, Campus Lübeck and Klinikum Bad Bramstedt, Germany. ${ }^{2}$ Department of Pulmology, University Hospital Schleswig-Holstein, Campus Lübeck, Germany.

Published: 30 June 2011

\section{References}

1. Fries JF, Hunder GG, Bloch DA, Michel BA, Arend WP, Calabrese LH, Fauci AS, Leavitt RY, Lie JT, Lightfoot RW Jr, et al.: The American College of Rheumatology 1990 criteria for the classification of vasculitis. Summary. Arthritis Rheum 1990, 33:1135-1136.

2. Jennette JC, Falk RJ, Andrassy K, Bacon PA, Churg J, Gross WL, Hagen EC, Hoffman GS, Hunder GG, Kallenberg CG, et al:: Nomenclature of systemic vasculitides. Proposal of an international consensus conference. Arthritis Rheum 1994, 37:187-192.

3. Hoffman GS, Kerr GS, Leavitt RY, Hallahan CW, Lebovics RS, Travis WD, Rottem M, Fauci AS: Wegener granulomatosis: an analysis of 158 patients. Ann Intern Med 1992, 116:488-498.

4. Reinhold-Keller E, Beuge N, Latza U, de Groot K, Rudert H, Nölle B, Heller M, Gross WL: An interdisciplinary approach to the care of patients with Wegener's granulomatosis: long-term outcome in 155 patients. Arthritis Rheum 2000, 43:1021-1032.

5. Falk RJ, Terrell RS, Charles LA, Jennette JC: Anti-neutrophil cytoplasmic autoantibodies induce neutrophils to degranulate and produce oxygen radicals in vitro. Proc Natl Acad Sci U S A 1990, 87:4115-4119.

6. Calderwood JW, Williams JM, Morgan MD, Nash GB, Savage CO: ANCA induces beta2 integrin and CXC chemokine-dependent neutrophilendothelial cell interactions that mimic those of highly cytokine-activated endothelium. J Leukoc Biol 2005, 77:33-43.

7. Xiao H, Heeringa P, Hu P, Liu Z, Zhao M, Aratani Y, Maeda N, Falk RJ, Jennette $J C$ : Antineutrophil cytoplasmatic antibodies specific for myeloperoxidase cause glomerulonephritis and vasculitis in mice. J Clin Invest 2002, 110:955-963.

8. Fienberg R: Pathergic granulomatosis. Am J Med 1955, 19:829-831.

9. European therapeutic trials in ANCA-associated systemic vasculitis: disease scoring, consensus regimens and proposed clinical trials. European Community Study Group on Clinical Trials in Systemic Vasculitis ECSYSVASTRIAL. Clin Exp Immunol 1995, 101 (suppl 1):29-34.

10. Hellmich B, Flossmann O, Gross WL, Bacon P, Cohen-Tervaert JW, Guillevin L, Jayne D, Mahr A, Merkel PA, Raspe H, Scott DG, Witter J, Yazici H, Luqmani RA: EULAR recommendations for conducting clinical studies and/or clinical trials in systemic vasculitis: focus on anti-neutrophil cytoplasm antibodyassociated vasculitis. Ann Rheum Dis 2007, 66:605-617. 
11. Mukhtyar C, Guillevin L, Cid MC, Dasgupta B, de Groot K, Gross W, Hauser T, Hellmich B, Jayne D, Kallenberg CG, Merkel PA, Raspe H, Salvarani C, Scott DG, Stegeman C, Watts R, Westman K, Witter J, Yazici H, Luqmani R; European Vasculitis Study Group: EULAR recommendations for the management of primary small vessel vasculitis. Ann Rheum Dis 2009, 68:310-317.

12. Anderson G, Coles ET, Crane M, Douglas AC, Gibbs AR, Geddes DM, Peel ET, Wood JB: Wegener's granuloma. A series of 265 British cases seen between 1975 and 1985. A report by a sub-committee of the British Thoracic Society Research Committee. QJM 1992, 83:427-438.

13. Holle JU, Gross WL, Holl-Ulrich K, Ambrosch P, Noelle B, Both M, Csernok E, Moosig F, Schinke S, Reinhold-Keller E: Prospective long-term follow-up of patients with localized Wegener's granulomatosis: does it occur as persisten disease stage? Ann Rheum Dis 2010, 69:1934-1939.

14. Reuter M, Schnabel A, Wesner F, Tetzlaff K, Risheng Y, Gross WL, Heller M: Pulmonary Wegnener's granulomatosis: correlation between highresolution CT findings and clinical scoring of disease activity. Chest 1998, 114:500-506.

15. Komócsi A, Reuter M, Heller M, Muraközi H, Gross WL, Schnabel A: Active disease and residual damage in treated Wegener's granulomatosis: an observational study using pulmonary high-resolution computed tomography. Eur Radiol 2003, 13:36-42.

16. Haworth SJ, Savage CO, Carr D, Hughes JM, Rees AJ: Pulmonary haemorrhage complicating Wegener's granulomatosis and microscopic polyarteriitis. BMJ 1985, 290:1775-1778.

17. Thickett DR, Richter AG, Nathani N, Perkins GD, Harper L: Pulmonary manifestations of anti-neutrophil cytoplasmic antibody (ANCA-) positive vasculitis. Rheumatology 2006, 45:261-268.

18. Schnabel A, Reuter M, Gloeckner K, Müller-Quernheim J, Gross WL: Bronchoalveolar lavage cell profiles in Wegener's granulomatosis. Respir Med 1999, 93:498-506.

19. Guillevin L, Durand-Gasselin B, Cevallos R, Gayraud M, Lhote F, Callard P, Amouroux J, Casassus P, Jarrousse B: Microscopic polyangiitis: clinical and laboratory findings in eighty-five patients. Arthritis Rheum 1999, 42:421-430.

20. Mahr A, Guillevin L, Poissonnet M, Aymé S: Prevalences of polyarteriitis nodosa, microscopic polyangiitis, Wegener's granulomatosis and ChurgStrauss syndrome in a French urban multiethnic population in 2000: a capture-recapture estimate. Arthritis Rheum 2004, 51:92-99.

21. Savage CO, Winearls CG, Evans DJ, Rees AJ, Lockwood CM: Microscopic polyarteriitis: presentation, pathology and prognosis. QJMed 1985, 56:467-483

22. Lhote F, Cohen P, Guillevin L: Polyarteritis nodosa, microscopic polyangiitis and Churg-Strauss syndrome. Lupus 1998, 7:238-258.

23. Hervier B, Pagnoux C, Agard C, Haroche J, Amoura Z, Guillevin L, Hamidou MA; French Vasculitis Study Group: Pulmonary firbosis associated with ANCA-positive vasculitides. Retrospective study of 12 cases and review of the literature. Ann Rheum Dis 2009, 68:404-407.

24. Becker-Merok A, Nossent JC, Ritland N: Fibrosing alveolitis predating mocroscopic polyangiitis. Scand J Rheumatol 1999, 28:254-256.

25. Birnbaum J, Danoff S, Askin FB, Stone JH: Microscopic polyangiitis presenting as a "pulmonary-muscle" syndrome: is subclinical alveolar hemorrhage the mechanism of pulmonary fibrosis? Arthritis Rheum 2007, 56:2065-2071.

26. Tzelepis GE, Kokosi M, Tzioufas A, Toya SP, Boki KA, Zormpala A, Moutsopoulos HM: Prevalence and outcome of pulmonary fibrosis microscopic polyangiitis. Eur Respir J 2010, 36:1 16-121.

27. Sinico RA, Di Toma L, Maggiore U, Bottero P, Radice A, Tosoni C, Grasselli C, Pavone L, Gregorini G, Monti S, Frassi M, Vecchio F, Corace C, Venegoni E, Buzio C: Prevalence and clinical significance of antineutrophil cytoplasmic antibodies in Churg-Strauss syndrome. Arthritis Rheum 2005, 52:2926-2935.

28. Simon HU, Rothenberg ME, Bochner BS, Weller PF, Wardlaw AJ, Wechsler ME, Rosenwasser LJ, Roufosse F, Gleich GJ, Klion AD: Refining the definition of hypereosinophilic syndrome. J Allergy Clin Immunol 2010, 126:45-49.

29. Lanham JG, Elkon KB, Pusey CD, Hughes GR: Systemic vasculitis with asthma and eosinophilia: a clinical approach to the Churg-Strauss syndrome. Medicine (Baltimore) 1984, 63:65-81.

30. Pagnoux C, Guilpain P, Guillevin L: Churg-Strauss syndrome. Curr Opin Rheumatol 2007, 19:25-32.

31. Dennert RM, van Paassen P, Schalla S, Kuznetsova T, Alzand BS, Staessen JA, Velthuis S, Crijns HJ, Tervaert JW, Heymans S: Cardiac involvement in Churg-Strauss syndrome. Arthritis Rheum 2010, 62:627-634.
32. Wieczorek S, Hellmich B, Arning L, Moosig F, Lamprecht P, Gross WL, Epplen $J T$ : Functionally relevant variations of the interleukin- 10 gene associated with antineutrophil cytoplasmic antibody-negative Churg-Strauss syndrome, but not with Wegener's granulomatosis. Arthritis Rheum 2008, 58:1839-1848

33. Churg J, Strauss L: Allergic angiitis and periarteritis nodosa. Am J Pathol 1951, 27:277-301.

34. Guillevin L, Lhote F, Gayraud M, Cohen P, Jarrousse B, Lortholary O, Thibult N, Casassus P: Prognostic factors in polyarteritis nodosa and Churg-Strauss syndrome. A prospective study in 342 patients. Medicine (Baltimore) 1996, 75:17-28.

35. Ribi C, Cohen P, Pagnoux C, Mahr A, Arène JP, Lauque D, Puéchal X, Letellier $P$, Delaval P, Cordier JF, Guillevin L; French Vasculitis Study Group: Treatment of Churg-Strauss syndrome without poor-prognosis factors: a multicenter, prospective, randomized, open-label study of seventy-two patients. Arthritis Rheum 2008, 58:586-594.

36. Keogh KA, Specks U: Churg-Strauss Syndrome. Clinical presentation antineutrophil cytoplasmic antibodies, and leukotriene receptor antagonists. Am J Med 2003, 115:284-290.

37. Cottin V, Kouatra C, Dubost R: Persistent airflow obstruction in asthma of patients with Churg-Strauss syndrome. Allergy 2009, 64:589-595.

38. Bibby S, Healy B, Steele R, Kumareswaran K, Nelson H, Beasley R: Association between leukotriene receptor antagonist therapy and Churg-Strauss syndrome: an analysis of the FDA AERS database. Thorax 2010, 65:132-138,

39. Schnabel A, Csernok E, Braun J, Gross WL: Inflammatory cells and cellular activation in the lower respiratory tract in Churg-Strauss syndrome. Thorax 1999, 54:771-778.

40. Luqmani RA, Bacon PA, Moots RJ, Janssen BA, Pall A, Emery P, Savage C, Adu D: Birmingham Vasculitis Activity Score (BVAS) in systemic necrotizing vasculitis. QJM 1994, 87:671-681.

41. Exley AR, Bacon PA, Luqmani RA, Kitas GD, Gordon C, Savage CO, Adu D: Development and initial validation of the Vasculitis Damage Index for the standardized clinical assessment of damage in the systemic vasculitides. Arthritis Rheum 1997, 40:371-380.

42. De Groot K, Rasmussen N, Bacon PA, Tervaert JW, Feighery C, Gregorini G, Gross WL, Luqmani R, Jayne DR: Randomized trial of cyclophosphamide versus methotrexate for induction of remission in early systemic antineutrophil cytoplasmic antibody-associated vasculitis. Arthritis Rheum 2005, 52:2461-2469.

43. de Groot K, Harper L, Jayne DR, Flores Suarez LF, Gregorini G, Gross WL, Luqmani R, Pusey CD, Rasmussen N, Sinico RA, Tesar V, Vanhille P, Westman K, Savage CO; EUVAS (European Vasculitis Study Group): Pulse versus daily oral cyclophosphamide for induction of remission in antineutrophil cytoplasmic antibody-associated vasculitis: a randomized trial. Ann Intern Med 2009, 150:670-680

44. Stone JH, Merkel PA, Spiera R, Seo P, Langford CA, Hoffman GS, Kallenberg CG, St Clair EW, Turkiewicz A, Tchao NK, Webber L, Ding L, Sejismundo LP, Mieras K, Weitzenkamp D, Ikle D, Seyfert-Margolis V, Mueller M, Brunetta P, Allen NB, Fervenza FC, Geetha D, Keogh KA, Kissin EY, Monach PA, Peikert T, Stegeman C, Ytterberg SR, Specks U; RAVE-ITN Research Group: Rituximab versus cyclophosphamide for ANCA-associated vasculitis. N Engl J Med 2010, 363:221-232.

45. Jones RB, Tervaert JW, Hauser T, Luqmani R, Morgan MD, Peh CA, Savage CO, Segelmark M, Tesar V, van Paassen P, Walsh D, Walsh M, Westman K, Jayne DR; European Vasculitis Study Group: Rituximab versus cyclophopshamide in ANCA-associated renal vasculitis. N Eng/ J Med 2010, 363:211-220.

46. Jayne DR, Gaskin G, Rasmussen N, Abramowicz D, Ferrario F, Guillevin L, Mirapeix E, Savage CO, Sinico RA, Stegeman CA, Westman KW, van der Woude FJ, de Lind van Wijngaarden RA, Pusey CD; European Vasculitis Study Group: Randomized trial of plasma exchange or high-dosage methylprednisolone as adjunctive therapy for severe renal vasculitis. J Am Soc Nephrol 2007, 18:2180-2188.

47. Jayne D, Rasmussen N, Andrassy K, Bacon P, Tervaert JW, Dadoniené J, Ekstrand A, Gaskin G, Gregorini G, de Groot K, Gross W, Hagen EC, Mirapeix E, Pettersson E, Siegert C, Sinico A, Tesar V, Westman K, Pusey C; European Vasculitis Study Group: A randomized trial of maintenance therapy for vasculitis associated with antineutrophil cytoplasmic autoantibodies N Engl J Med 2003, 349:36-44.

48. Pagnoux C, Mahr A, Hamidou MA, Boffa JJ, Ruivard M, Ducroix JP, Kyndt X, Lifermann F, Papo T, Lambert M, Le Noach J, Khellaf M, Merrien D, Puéchal X, Vinzio S, Cohen P, Mouthon L, Cordier JF, Guillevin L; French Vasculitis Study 
Group: Azathioprine of methotrexate maintenance for ANCA-associated vasculitis. N Eng/ J Med 2008, 359:2790-2803.

49. Metzler C, Miehle N, Manger K, Iking-Konert C, de Groot K, Hellmich B, Gross WL, Reinhold-Keller E; German Network of Rheumatic Diseases: Elevated relapse rate under oral methotrexate versus leflunomide for maintenance of remission in Wegener's granulomatosis. Rheumatology 2007, 46:1087-1091.

50. Stegeman CA, Tervaert JW, de Jong PE, Kallenberg CG: Trimethoprimsulfamethoxazole (co-trimoxazole) for the prevention of relapses of Wegener's granulomatosis. Dutch Co-Trimoxazole Wegener Study Group. NEngl J Med 1996, 335:16-20.

51. Reinhold-Keller E, De Groot K, Rudert H, Nölle B, Heller M, Gross WL: Response to trimethoprim/sulfamethoxazole in Wegener's granulomatosis depends on the phase of disease. QJM 1996, 89:15-23.

52. Mahr A, Girard T, Agher R, Guillevin L: Analysis of factors predictive of survival based on 49 patients with systemic Wegener's granulomatosis and prospective follow-up. Rheumatology 2001, 40:492-498.

53. Bligny D, Mahr A, Toumelin PL, Mouthon L, Guillevin L: Predicting mortality in systemic Wegener's granulomatosis: a survival analysis based on 93 patients. Arthritis Rheum 2004, 51:83-91.

54. Matteson EL, Gold KN, Bloch DA: Long-term survival of patients with Wegener's granulomatosis from the American College of Rheumatology Wegener's granulomatosis classification cohort. Am J Med 1996, 101:129-134.

55. Lane SE, Watts RA, Shepstone L, Scott DG: Primary systemic vasculitis: clinical features and mortality. QJM 2005, 98:97-111.

56. Aasarød K, Iversen BM, Hammerstrøm J, Bostad L, Vatten L, Jørstad S: Wegener's granulomatosis: clinical course in 108 patients with renal involvement. Nephrol Dial Transplant 2000, 15:611-618.

57. Knight A, Askling J, Ekbom A: Cancer incidence in a population-based cohort of patients with Wegener's granulomatosis. Int J Cancer 2002, 100:82-85.

58. Eriksson P, Jacobsson L, Lindell A, Nilsson JA, Skogh T: Improved outcome in Wegener's granulomatosis and microscopic polyangiitis? A retrospective analysis of 95 cases in two cohorts. J Intern Med 2009, 265:496-506.

59. Holle JU, Gross WL, Latza U, Nölle B, Ambrosch P, Heller M, Fertmann R, Reinhold-Keller E: Improved outcome of 445 Wegener's granulomatosis patients in a German vasculitis center over four decades. Arthritis Rheum 2010, 63:257-266.

60. Little MA, Nightingale P, Verburgh CA, Hauser T, De Groot K, Savage C, Jayne D, Harper L; European Vasculitis Study (EUVAS) Group: Early mortality in systemic vasculitis: relative contribution of adverse events and active vasculitis. Ann Rheum Dis 2010, 69:1036-1043.

61. Metzler C, Hellmich B, Gause A, Gross WL, de Groot K: Churg-StraussSyndrome- successful induction of remission with methotrexate and unexpected high cardiac and pulmonary relapse ratio during maintenance therapy. Clin Exp Rheumatol 2004, 22:S52-61.

62. Solans R, Bosch JA, Pérez-Bocanegra C, Selva A, Huguet P, Alijotas J, Orriols R, Armadans $L$, Vilardell M: Churg-Strauss syndrome: outcome and longterm follow-up of 32 patients. Rheumatology 2001, 40:763-771.

63. Tatsis E, Schnabel A, Gross WL: Interferon-a treatment of four patients with the Churg-Strauss-Syndrome. Ann Int Med 1998, 129:370-374.

64. Metzler C, Schnabel A, Gross WL, Hellmich B: A phase II study of interferonalpha for the treatment of refractory Churg-Strauss syndrome. Clin Exp Rheumatol 2008, 26:S35-40

65. Pepper RJ, Fabre MA, Pavesio C, Gaskin G, Jones RB, Jayne D, Pusey CD, Salama AD: Rituximab is effective in the treatment of refractory ChurgStrauss syndrome and is associated with diminished T-cell interleukin-5 production. Rheumatology (Oxford) 2008, 47:1 104-1105

66. Arbach O, Gross WL, Gause A: Treatment of refractory Churg-StraussSyndrome (CSS) by TNF-alpha blockade. Immunobiology 2002, 206:496-501.

67. Kim S, Marigowda G, Oren E, Israel E, Wechsler ME: Mepolizumab as a steroid-sparing treatment option in patients with Churg-Strauss syndrome. J Allergy Clin Immunol 2010, 125:1336-1343.

68. Moosig F, Butherus K, Hellmich B, Gross WL: Mepolizumab, a humanized IL-5 antibody, has steroid-sparing potential in Churg-Strauss-Syndrome. Arthritis Rheum 2010, 62:S925.

69. Chan AL, Louie S, Leslie KO, Juarez MM, Albertson TE: Cutting edge issues in Goodpasture's disease. Clin Rev Allergy /mmunol 2011 [Epub ahead of print].

70. Saulsbury T: Henoch-Schönlein purpura. Curr Opin Rheumatol 2010, 22:598-602.
71. Ferri C, Mascia MT: Cryoglobulinemic vasculitis. Curr Opin Rheumatol 2006, 18:54-63.

72. Pagnoux C, Seror R, Henegar C, Mahr A, Cohen P, Le Guern V, Bienvenu B, Mouthon L, Guillevin L; French Vasculitis Study Group: Clinical features and outcomes in 348 patients with polyarteritis nodosa. Arhtritis Rheum 2010, 62:616-626.

73. Mukhtyar C, Guillevin L, Cid MC, Dasgupta B, de Groot K, Gross W, Hauser T, Hellmich B, Jayne D, Kallenberg CG, Merkel PA, Raspe H, Salvarani C, Scott DG Stegeman C, Watts R, Westman K, Witter J, Yazici H, Luqmani R; European Vasculitis Study Group: EULAR recommendations for the management of large vessel vasculitis. Ann Rheum Dis 2009, 68:310-317.

74. Mason C: Takayasu arteritis- advances in diagnosis and treatment. Nat Rev Rheumatol 2010, 6:406-415

75. Ceylan N, Bayraktaroglu S, Erturk SM, Savas R, Alper H: Pulmonary and vascular manifestations of Behcet disease: Imaging findings. AJRAm Roentgenol 2010, 194:W158-W164

76. Hatemi G, Silman A, Bang D, Bodaghi B, Chamberlain AM, Gul A, Houman MH, Kötter I, Olivieri I, Salvarani C, Sfikakis PP, Siva A, Stanford MR, Stübiger N, Yurdakul S, Yazici H; EULAR Expert Committee: EULAR recommendations for the management of Behcet disease. Ann Rheum Dis 2008, 67:1656-1662.

77. Stassen PM, Derks RP, Kallenberg CG, Stegeman CA: Venous thromboembolism in ANCA-associated vasculitis - incidence and risk factors. Rheumatology 2008, 47:530-534.

78. Csernok E, Lamprecht P, Gross WL: Clinical and immunological features of drug-indeuced and infection-induced proteinase 3-antirneutrophil cytoplasmic antibodies and myeloperoxidase-antineutrophil cytoplasmic antibodies and vasculitis. Curr Opin Rheumatol 2010, 22:43-48.

79. Hogan SL, Cooper GS, Savitz DA, Nylander-French LA, Parks CG, Chin H, Jennette CE, Lionaki S, Jennette JC, Falk RJ: Association of silica exposure with anti-neutrophil cytoplasmic autoantibody small-vessel vasculitis: a population-based case-control study. Clin J AM Soc Nephrol 2007, 2:290-299.

80. Knight A, Sandin S, Askling J: Occupational risk factors for Wegener's granulomatosis: a case-control study. Ann Rheum Dis 2010, 69:737-740.

81. Moosig F, Holle JU, Gross WL: Value of anti-infective chemoprophylaxis in primary systemic vasculitis: what is the evidence? Arthritis Res Ther 2009, 11:253.

82. Guillevin L, Cordier JF, Lhote F, Cohen P, Jarrousse B, Royer I, Lesavre P, Jacquot C, Bindi P, Bielefeld P, Desson JF, Détrée F, Dubois A, Hachulla E, Hoen B, Jacomy D, Seigneuric C, Lauque D, Stern M, Longy-Boursier M: A prospective multicenter randomized trial comparing steroids and pulse cyclophosphamide versussteroids and oral cyclophosphamide in the treatment of generalized Wegener's granulomatosis. Arthritis Rheum 1997, 40:2187-2198

83. Falk RJ, Hogan S, Carey TS, Jennette JC: Clinical course of anti-neutrophil cytoplasmic autoantibody-associated glomerulonphritis and systemic vasculitis. Ann Intern Med 1990, 113:656-663.

84. Charlier C, Henegar C, Launay O, Pagnoux C, Berezné A, Bienvenu B, Cohen P, Mouthon L, Guillevin L: Risk factors for major infections in Wegener granulomatosis: analysis of 113 patients. Ann Rheum Dis 2009, 68:658-663.

85. Jones RB, Ferraro AJ, Chaudhry AN, Brogan P, Salama AD, Smith KG, Savage $\mathrm{CO}$, Jayne DR: A multicenter survey of rituximab therapy for refractory antineutrophil cytoplasmic antibody-associated vasculitis. Arthritis Rheum 2009, 60:2156-2168.

86. Flossmann O, Baslund B, Bruchfeld A, Tervaert JW, Hall C, Heinzel P, Hellmich B, Luqmani RA, Nemoto K, Tesar V, Jayne DR: Deoxyspergualin in relapsing and refractory Wegener's granulomatosis. Ann Rheum Dis 2009, 68:1125-1130.

87. Schmitt WH, Hagen EC, Neumann I, Nowack R, Flores-Suárez LF, van der Woude FJ; European Vasculitis Study Group: Treatment of refractory Wegener's granulomatosis with antithymocyte globulin (ATG): an open study in 15 patients. Kidney Int 2004, 65:1440-1448.

88. Ognibene FP, Shelhamer JH, Hoffman GS, Kerr GS, Reda D, Fauci AS, Leavitt RY: Pneumocystis carinii pneumonia: a major complication of immunosuppressive therapy in patients with Wegener's granulomatosis. Am J Respir Crit Care Med 1995, 151:795-799.

89. Godeau B, Mainardi JL, Roudot-Thoraval F, Hachulla E, Guillevin L, Huong Du LT, Jarrousse B, Remy P, Schaeffer A, Piette JC: Factors associated with Pneumocystis carinii pneumonia in Wegener's granulomatosis. Ann Rheum Dis 1995, 54:991-994

90. Swoden E, Carmicheal AJ: Autoimmune inflammatory disorders, systemic 
corticosteroids and pneumocystis pneumonia: a strategy for prevention. BMC Infect Dis 2004, 4:42-48.

91. Yale SH, Limper AH: Pneumocystis carinii pneumonia in patients without acquired immunodeficiency syndrome: associated illness and prior corticosteroid therapy. Mayo Clin Prof 1996, 71:5-13.

92. Bligny D, Mahr A, Toumelin PL, Mouthon L, Guillevin L: Predicting mortality in systemic Wegener's granulomatosis: a survival based analysis based on 93 patients. Arthritis Rheum 2004, 51:83-91.

93. Mahr A, Girard T, Agher R, Guillevin L: Analysis of factors predictive of survival based on 49 patients with systemic Wegener's granulomatosis and prospective follow-up. Rheumatology 2001, 40:492-498.

doi:10.1186/ar3307

Cite this article as: Holle JU, et al:: Conditions in subjects with rheumatic diseases: pulmonary manifestations of vasculitides. Arthritis Research \&

Therapy 2011, 13:224. 